'convectional' theories-as necessary for a complete explanation.

Since I920 several further contributions have been made to the literature of tropical cyclones. One deals with the region around the West Indies. ${ }^{4}$ Redrawing the tracks of all known cyclones in this area since I886, Mitchell found that no storm originated over the eastern. two-thirds of the Caribbean Sea; many storms originated, however, south of the Cape Verde Islands, and some over the western third of the Caribbean Sea. The deciding factor in this case, as for the Indian cyclones, appears to be the presence or absence of a discontinuity between conflicting winds; such a discontinuity is absent over the eastern two-thirds of the Caribbean Sea. Another interesting fact pointed out by Mitchell is that the cyclone of this area 'recurves' (i.e. turns directly polewards) as soon as a trough of low pressure arrives to the north, irrespective of the longitude and time of year.

Another recent valuable publication deals statistically with the tropical cyclones of Australia, without, however, contributing much that is new to the theory

4 "West Indian Hurricanes and other Tropical Cyclones of the North Atlantic Ocean." By C. L. Mitchell. Monthly Weather Review. Supplement No. 24, 1924. of the storms. ${ }^{5}$ The last paper to which I shall refer is concerned with the dynamics of the formation of cyclones. ${ }^{6}$ Capt. Brunt follows Shaw in regarding simple thermal convection of moist air as the initial stage, the energy for the subsequent violent winds being supplied by the latent heat of condensation of the water vapour that is precipitated in the rising column of air before those winds arise. He lays stress on the importance of explaining how the removal of air from the centre of a developing storm is brought about, and presumes that it is effected by the discharge of the column of rising air into strong upper winds.

The verification or refutation of this and of the various alternative theories of the origin of cyclones that have been brought forward, which space does not permit me to describe, awaits a more complete knowledge of the temperature, humidity, and wind at all levels in the regions of formation of cyclones, which are unfortunately in most cases just where observations of any kind are most difficult to obtain.

\footnotetext{
" "Australian Hurricanes and Related Storms." By S. Visher and D. Hodge, I925.

" "The Origin of Tropical Revolving Storms." By D. Brunt, London Meteorological Office. Marine Observer, r 924.
}

\title{
The Reported Conversion of Hydrogen into Helium.
}

$\mathrm{T}^{\mathrm{HE}}$ current (September) issue of the Berichte of the German Chemical Society contains a paper by Profs. F. Paneth and K. Peters on "The Transformation of Hydrogen into Helium," in which they describe in outline how they have succeeded in detecting the presence of very minute amounts of helium, of the order of one hundred millionth of a cubic centimetre, derived from hydrogen which had been absorbed by finely divided palladium at the ordinary temperature.

Theory indicating that this conversion would involve the liberation of much energy $\left(6.4 \times 10^{11} \mathrm{cal}\right.$. from 4 gram-atoms of hydrogen), the author's primary task was to find out if the change would take place without introducing energy from outside, e.g. in the presence of a catalyst ; and in order to be able to detect very small quantities of helium they elaborated the spectroscopic method in such a way that the limiting amount detectable was $10^{-8}-10^{-9}$ c.c., or $10^{-12}-10^{-13} \mathrm{gm}$. Easily liquefiable gas was removed with liquid air and charcoal ; oxygen was added and the hydrogen burnt on the surface of the catalyst; water-vapour and excess oxygen were removed with charcoal, and the residual gas was passed into a glass capillary-tube of $0.1 \mathrm{~mm}$. section, which was surrounded with electrode-wires and placed before the slit of the spectroscope. Every precaution was taken to exclude atmospheric helium; the portion of the apparatus that was heated was surrounded with a vacuum-mantle and immersed in water. The presence of neon lines afforded a most valuable criterion of the presence of atmospheric gases; neon was never completely excluded, but the amount present was so small that it did not invalidate the author's main conclusion.

The method is so delicate that the liberation of helium from a mixture of thorium $\mathrm{B}$ and thorium $\mathrm{C}$ was easily detected, while it is sufficiently sensitive to determine the presence of helium in a few cubic centimetres of natural gas. By its means a natural gas containing O.I9 per cent. by volume of helium was discovered in Germany, and steps have been taken to exploit it commercially. The Canadian natural gas from which helium is extracted contains 0.33 per cent. by volume.

Attempts were made to effect the transformation by submitting hydrogen to the action of a silent electric discharge in an ozone apparatus, and by passing a prolonged and powerful discharge through it in a Geissler-tube fitted with aluminium electrodes; but no success was achieved. Nor was the attempt to produce helium by bombarding certain salts with cathode rays, as suggested by Lord Rayleigh, any more fertile, so that recourse was had to passing fairly large amounts of hydrogen-up to one litre--through heated palladium, in the hope that at the moment of exit a fraction of the protons and electrons would combine to form the helium nucleus. In this case the indications were favourable, but the result was inconclusive owing to the presence of atmospheric neon, and the absence of any proportionality between the strength of the helium lines and the amount of hydrogen that was used.

Finely-divided palladium, either as sponge, 'black,' or palladinised asbestos, was then used to absorb hydrogen at room temperature, and after different intervals of time the hydrogen was combined with oxygen, as previously described. The residual gas obtained after a I 2 -hours' contact between palladium and hydrogen exhibited four or five lines of the helium spectrum and only a single neon-line; there was also a distinct proportionality between the amount of helium observed and the duration of the time of contact. The activity of the different palladium preparations employed varied considerably ; it invariably diminished with repeated use, but both the power of absorbing hydrogen and of effecting the transformation were restored by heating in hydrogen or oxygen, in a mixture 
of these gases, or in a vacuum. No helium production was observed with palladium preparations that did not absorb hydrogen, although preparations were occasionally obtained that absorbed hydrogen well but gave little of no helium, especially if the hydrogen had been absorbed at a high temperature.

The above results indicated that palladium preparations that have long remained unused at room temperature should contain a little helium (not of atmospheric origin). Examination of a number of such specimens showed that helium was present in all of them, and in particular a specimen of palladinised asbestos, which had been purchased from Kahlbaum two years previously, was found to be relatively very rich, I gm. of it containing $\mathrm{IO}^{-6}$ c.c. of practically pure helium. After this specimen had been heated to expel the helium, and treated with oxygen for twelve hours, no fresh helium was detected, but at the end of five hours in contact with hydrogen a considerable amount of helium was found. This experiment was performed three times with the same result. The palladium, however, gradually lost its activity; at the beginning it produced helium at the rate of $1^{-8}{ }^{-1} \mathrm{IO}^{-7}$ c.c. per day ; after twenty treatments it became inactive. Its activity was restored, although not to the original degree, in the manner described above. Finely divided platinum is less active than palladium, and the action of pyrophoric nickel is weaker still.

The authors discuss fully the possible sources of error in their experiments, such as the ingress of atmospheric helium, the adsorptive capacity of glass for helium, the conceivable preferential adsorption of helium by palladium, or by asbestos, and the possibility of helium being formed as a radio-active disintegration product of palladium; all of which they consider to be excluded. The hydrogen and oxygen used by them contained less than 0.001 per cent. of air. They were not able to detect any trace of the energy liberated during the transformation, and they point out that the amount set free from the conversion of such small quantities of hydrogen-about 0.28 calorie-would be extremely difficult to detect, and particularly so if thermal changes due to absorption or formation of compounds also take place. They incline to the view that the liberated energy is more likely to appear as radiation, e.g. as $\gamma$ or Millikan-rays, than as heat.

\section{News and Views.}

ONE of the subjects discussed at the recent World Power Conference at Basle was the exchange of electrical energy between countries. An interesting example of this interchange of energy occurs between Denmark and Sweden. Submarine cables crossing the Sund Straits transmit power at 25,000 volts and 50,000 volts respectively. When the water supply in Sweden is abundant they carry the excess hydroelectric power to Denmark, and when Sweden suffers from water shortage they convey thermally generated power in the reverse direction. It was pointed out that some countries, Switzerland for example, have great water power resources but yet are very unwilling to export electric power, and set up high tariffs. One of the reasons for their action would appear to be that, in the opinion of some Swiss engineers, Switzerland is destined to become one of the important centres for carrying out electrometallurgical and electrochemical processes on a large scale. In their opinion, the sale of electrical energy abroad helps the establishment of those industries outside their own frontiers and so is not in the national interest. Another objection is that the export of electricity in bulk to foreign countries will gradually subordinate Switzerland to these countries; the foreign capital introduced being conceivably a source of danger. Mr. Niesz of Baden held that these objections have no real foundation. The majority of the engineers present agreed that it is desirable that the authorities in different countries should place no obstacle in the way of a free interchange of electrical energy provided that economic conditions are favourable.

Mr. Alan Coвнam alighted on the Thames opposite the Houses of Parliament on October I, thus completing his latest flying achievement. In recognition of his services to aviation the King has conferred upon Mr. Cobham the honour of knighthood (K.B.E.). His three long-distance flights are a notable advertisement for commercial aviation. The De Havilland-5o aeroplane, with Armstrong-Siddely "Puma" engine and interchangeable floats and wheels, was designed for flying in countries with undeveloped transport services, where lake, river, or sea offer natural alighting places. An aeroplane of this type was flown to Rangoon and back. The same aeroplane fitted with the more powerful " Jaguar" engine was flown to the Cape and back. Finally, the same aeroplane and engine, after overhaul and fitting of forged "Y-metal" aluminium pistons, was flown to Melbourne and back, floats being fitted as far as Port Darwin, wheels for trans-Australian flying. The structural alterations required for the heavier engine, if any, are not known, but the following are some of the main characteristics:

\begin{tabular}{|c|c|c|}
\hline D.H.-5o. & Puma Engine. & $\begin{array}{c}\text { Jaguar (Radial) } \\
\text { Engine. }\end{array}$ \\
\hline 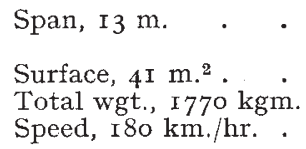 & $\begin{array}{l}6 \text { cyl. (water } \\
\text { cooled). } \\
\text { I } 80 \mathrm{kw} \text {. } \\
\text { I } 400 \text { r.p.m. } \\
\text { 300 kgm. wgt. }\end{array}$ & $\begin{array}{l}\text { I4 cyl. (air } \\
\text { cooled). } \\
290 \mathrm{kw} . \\
\text { I } 700 \mathrm{r} . \mathrm{p} . \mathrm{m} \text {. } \\
360 \mathrm{kgm} \text {. wgt. }\end{array}$ \\
\hline
\end{tabular}

The last of the three fights was equivalent to flying $800 \mathrm{~km}$. every other day from June 30 to October I, a high feat of personal skill and endurance, and an equally remarkable record of aeroplane and engine performance.

THE specificity of quinine in curing or relieving the symptoms of malaria has long been known. At the present time, the chief drawback to its use is its cost, due in part to the few areas in which the bark yielding the highest proportion of this alkaloid can be cultivated and in part to the restriction of output. Other drugs have therefore been tried in the treatment of this disease; the other crystalline alkaloids present in the more common variety of bark, quinidine, cinchonine, and possibly cinchonidine, have been

$$
\text { NO. } 297 \text { I, VOL. I I 8] }
$$

